\title{
Alimentação de vacas F1 Holandês x Zebu com suplementos nitrogenados e monensina sódica: avaliação do consumo, parâmetros ruminais e produção de leite
}

\author{
[Feeding F1 Holstein x Zebu cows with nitrogenated supplements and sodic monensin: \\ feed intake, ruminal parameters and milk production] \\ J.G. Laguna ${ }^{1}$, A.N. Rodrigues ${ }^{1}$, H.M. Saturnino ${ }^{2}$, J.R.M. Ruas ${ }^{3}$, S.G. Coelho ${ }^{2}$, R.B. Reis ${ }^{2}$ \\ ${ }^{1}$ Aluna de pós-graduação - Escola de Veterinária - Universidade Federal de Minas Gerais - Belo Horizonte, MG \\ ${ }^{2}$ Escola de Veterinária - Universidade Federal de Minas Gerais - Belo Horizonte, MG \\ ${ }^{3}$ Pesquisador Epamig-CTZM - Viçosa, MG
}

\begin{abstract}
RESUMO
Avaliaram-se suplementos nitrogenados contendo ou não monensina sódica, adicionados à silagem, sobre o consumo de matéria seca (CMS), a digestibilidade da MS (DMS) e a produção de vacas F1 Holandês x Zebu. Vacas $(\mathrm{n}=15)$ com 21 dias em lactação, produzindo 19,2kg/dia, foram distribuídas em um delineamento quadrado latino $5 \mathrm{X} 5$, com três vacas por tratamento $(\mathrm{T})$. Os $\mathrm{T}$ foram: 1 - concentrado durante as ordenhas e silagem de milho após as ordenhas (C.SM); 2- C.SM + nitromineral (C.SMNM); 3- C.SM + nitroproteico (C.SMNP), 4- C.SMNM + monensina (C.SMNM+MO) e 5- C.SMNP + monensina (C.SMNP+MO). Os suplementos NP e NM adicionados à SM, (C.SMNP e C.SMNM) aumentaram o CMS $(\mathrm{P}<0,05)$. A adição de monensina não alterou o CMS nem a DMS $(\mathrm{P}>0,05)$. A suplementação proteica não aumentou o acetato $(\mathrm{P}>0,05)$, mas aumentou o propionato e o butirato $(\mathrm{P}<0,05)$. A adição de $\mathrm{MO}$ ao $\mathrm{T}$ C.SMNP reduziu o propionato e o butirato $(\mathrm{P}<0,05)$ em relação ao T C.SMNP. A concentração de nitrogênio amoniacal aumentou $(\mathrm{P}<0,05)$ no T C.SMNM em relação ao T C.SM e não diferiu dos demais. As produções de leite nos T C.SMNP e C.SMNPMO foram maiores do que no T C.SM $(\mathrm{P}<0,05)$. Vacas do T C.SM foram mais eficientes produzindo leite do que as do T C.SMNM $(\mathrm{P}<0,05)$.
\end{abstract}

Palavras-chave: consumo, parâmetros ruminais, F1 Holandês-Zebu, monensina, suplementação proteica

\begin{abstract}
The objectives of this study were to evaluate consumption, ruminal parameters and milk production of F1 Holstein $x$ Zebu milking cows fed nitrogenated supplements with or without monensin added to the silage. Cows with 21 days on milk and producing initially 19.2kg of milk/day were distributed in a 5 X5 Latin square design with three replicates per treatment. The treatments $(T)$ were: 1 -concentrate fed during the milking time and corn silage fed after milking (C.SM); 2- C.SM + nitromineral(NM) (C.SMNM); 3- C.SM + nitroproteico (NP) (C.SMNP); 4- C.SMNM + monensin $(C . S M N M+M O)$ e 5-C.SMNP + monensin (C.SMNP+MO). The addition of NP e NM to the T C.SM increased the DMI when compared to C.SM $(P<0.05)$. The addition of monensin did not change the DMI $(P>0,05)$. The protein supplementation did not alter acetate $(P>0,05)$, but increased propionate and butyrate concentrations. $(P<0.05)$ The N-NH3 concentration increased $(P<0.05)$ only in T C.SMNM $(P<0.05)$. The addition of monensin to T C.SMNP decreased propionate and butyrate concentrations $(P<0.05)$ related to T C.SMNP. The milk production was greater in the C.SMNP treatments than T C.SM ( $P<0.05)$. Cows in T C.SM produced milk more efficiently than cows fed C.SMNM $(P<0.05)$, but did not differ from the others.
\end{abstract}

Keywords: consumption, ruminal parameters, F1 Holstein-Zebu, monensin, protein supplementation

\section{INTRODUÇÃO}

A busca pela produção eficiente de leite vem sendo acompanhada pelo ganho genético dos rebanhos, o qual demanda aperfeiçoamento no

Recebido em 5 de março de 2012

Aceito em 06 de fevereiro de 2013

E-mail: julianaguimarãeslaguna@gmail.com manejo, principalmente em relação à nutrição. Assim, algumas estratégias alimentares, como o uso de ionóforos, têm sido implementadas na pecuária, esperando-se, assim, melhorar a eficiência. Os ionóforos são antibióticos (Haney Jr. et al., 1967) que, a princípio, agem sobre a 
membrana celular das bactérias ruminais melhorando a eficiência energética e a utilização dos compostos nitrogenados e, assim, reduzindo a proteólise e a deaminação dos aminoácidos. Eles podem melhorar o desempenho e a eficiência alimentar (Lemenager et al., 1978) e reduzir a quantidade de excreta e de gases emitidos pelos ruminantes. Os ionóforos podem reduzir as desordens ruminais, alterar a ingestão alimentar, a digestibilidade (Bergen e Bates, 1984) e melhorar a produção de leite, segundo Van Der Werf et al. (1998) e Arieli et al. (2008).

Os objetivos deste estudo foram avaliar o consumo de alimentos, a digestibilidade dos nutrientes, os parâmetros ruminais e a produção de leite de vacas F1 Holandês-Zebu, que receberam concentrado durante as ordenhas e silagem de milho após as ordenhas adicionada ou não com suplementos proteicos com e sem a adição de monensina sódica.

\section{MATERIAL E MÉTODOS}

Foram utilizadas 15 vacas F1 Holandês-Zebu, com peso inicial de $558 \mathrm{~kg}$, escore da condição corporal de 3,5, média inicial de 21 dias em lactação e produzindo $19,2 \mathrm{~kg}$ de leite. As vacas foram distribuídas em cada grupo conforme a data do parto, a produção de leite antes do início do experimento e o peso vivo. Os animais foram distribuídos aleatoriamente em cinco tratamentos, em delineamento quadrado latino $5 \times 5$, sendo três vacas por tratamento, durante cinco períodos. As três vacas de cada tratamento foram alojadas em piquetes sem cobertura vegetal de $30 \mathrm{~m}^{2}$, onde ficaram confinadas durante todo o dia, exceto nos horários das ordenhas. Ao final de cada período experimental, os grupos foram rotacionados entre os piquetes.

Os períodos experimentais foram de 24 dias, sendo 18 dias de adaptação e seis dias de coleta de dados. As duas ordenhas diárias iniciavam às seis e às 14 horas e foram feitas com cria ao pé. Todas as crias mamaram antes de se iniciar a ordenha, por, aproximadamente, 40 segundos e após as ordenhas, por 20 a 30 minutos.

As dietas experimentais foram balanceadas, segundo o NRC (National..., 2001), para serem isoproteicas: tratamento 1: concentrado durante a ordenha e silagem de milho pós- ordenha (controle/C.SM); tratamento 2: C.SM + nitromineral EPAMIG (C.SMNM); tratamento 3: $\mathrm{C} . \mathrm{SM}+$ nitroproteico EPAMIG (C.SMNP); tratamento 4: C.SM + nitromineral EPAMIG + monensina sódica (Rumensin ${ }^{\circledR}$, Elanco Animal Health. Monensina sódica a 10\%) (MO) (C.SMNM+MO); tratamento 5: C.SM + nitroproteico EPAMIG + MO (C.SMNP+MO). Foram utilizados $2,5 \mathrm{~g} / \mathrm{vaca} / \mathrm{dia}$ de Rumensin ${ }^{\circledR}$, que supriu 250mg de monensina sódica.

O nitromineral (NM) EPAMIG continha 55\% de ureia, $14 \%$ de fosfato bicálcico, $20 \%$ de sal mineralizado (comercial), $5 \%$ de sal comum e $6 \%$ de sulfato de amônia, e foram fornecidas $250 \mathrm{~g} / \mathrm{vaca} /$ dia. O nitroproteico (NP) EPAMIG continha $81 \%$ de farelo se soja, $5,5 \%$ de ureia, $1,4 \%$ de calcário, $2,3 \%$ de fosfato bicálcico, $7,3 \%$ de sal mineralizado (comercial), $1,8 \%$ de sal branco, $0,7 \%$ de sulfato de amônia, e foram fornecidas $750 \mathrm{~g} / \mathrm{vaca} / \mathrm{dia}$. Cada animal recebeu $250 \mathrm{mg}$ de $\mathrm{MO}$, os quais foram misturados ao $\mathrm{NM}$ ou ao NP.

Os suplementos (NM, NP, NM+MO e NP+MO) foram fornecidos duas vezes ao dia, misturados à silagem de milho. Aproximadamente uma hora após a ordenha da manhã (7h40mim), foram fornecidos $40 \%$ do volumoso e $30 \%$ dos suplementos, e após a ordenha da tarde (14h30mim), foram fornecidos $60 \%$ do volumoso e $70 \%$ dos suplementos. O fornecimento de volumoso foi em quantidades que permitissem 5 a $10 \%$ de sobras no cocho. As sobras foram coletadas e pesadas diariamente antes da alimentação da manhã e antes da alimentação da tarde, para ajustar a quantidade oferecida.

A quantidade de concentrado foi ajustada conforme a produção individual de leite no préexperimento e semanalmente durante o período experimental. Durante os primeiros 20 dias em lactação, todas as vacas receberam $3 \mathrm{~kg}$ de concentrado na hora de cada ordenha $(6 \mathrm{~kg} / \mathrm{dia})$. A partir deste período, foi oferecido $1 \mathrm{~kg}$ de concentrado para cada $3 \mathrm{~kg}$ de leite a partir de $8 \mathrm{~kg}$ de leite produzido.

O concentrado era composto por $86 \%$ do concentrado Nutrilac 22 [Tecnutri®; PB \% $(22,0)$; cálcio (máx.-0,89\%); fósforo (mín.0,52\%); MM (máx.-7,52\%); EE (mín.- 3,21\%); matéria fibrosa (máx.-7,0\%); umidade (máx.$13,0 \%)$; NNP (4,2\%)] e 14\% de levedura. Foram 
fornecidos $75 \%$ do concentrado diário na ordenha da manhã e $25 \%$ na ordenha da tarde, devido ao manejo da ordenha da fazenda. $\mathrm{O}$ sal mineralizado foi fornecido à vontade e continha $8 \%$ de fósforo.

Para avaliar a produção de leite, esta foi mensurada em quatro ordenhas consecutivas no $21^{\circ}$ e no $22^{\circ}$ dias de cada período experimental. Os consumos diários do concentrado e do volumoso foram avaliados do $19^{\circ}$ ao $24^{\circ}$ dia de cada período experimental. Das quantidades dos alimentos oferecidos foram subtraídas as sobras nos cochos. Foram coletadas amostras do alimento oferecido e das sobras do $19^{\circ}$ ao $24^{\circ}$ dia de cada período, as quais foram armazenadas a $20^{\circ} \mathrm{C}$ para análises bromatológicas. Após o preparo do concentrado e dos suplementos com ou sem monensina, amostras foram retiradas e armazenadas a $-20^{\circ} \mathrm{C}$ para posteriores análises bromatológicas. As amostras congeladas dos alimentos oferecidos e das sobras do cocho de cada $\mathrm{T}$ foram descongeladas à temperatura ambiente (+ou- $25^{\circ} \mathrm{C}$ ) e foram feitos pools de cada T. De cada pool de amostras foram feitas análises bromatológicas, conforme a AOAC (Association..., 1997) e Van Soest (1991).

Para se estimar o CMS do volumoso, multiplicou-se o consumo médio de cada T pela porcentagem da matéria seca do volumoso. Para se determinar o CMS do concentrado, multiplicou-se o consumo médio na matéria natural pela porcentagem estimada da digestibilidade da matéria seca $(85 \%)$, devido à alta digestibilidade dos ingredientes utilizados na composição da ração. Para se estimar o CMS do concentrado, foi multiplicado o consumo de matéria natural pelo valor da MS do concentrado.

O consumo de matéria seca total foi determinado pela equação:

CMST $(\mathrm{kg}$ de MS $)=$ CMS do volumoso + CMS do concentrado.

Para se determinar a digestibilidade da matéria seca (DMS), a produção fecal foi estimada utilizando-se a LIPE® (cápsula com $500 \mathrm{mg}$ ), com início no $19^{\circ}$ e término no $23^{\circ}$ dia de cada período experimental. O fornecimento da LIPE® foi como proposto por Silva et al. (2010).

As amostras de conteúdo ruminal foram colhidas no $24^{\circ}$ dia de cada período experimental e os procedimentos de coleta e as medições de $\mathrm{pH}$ foram feitos como descrito por Oliveira et al. (2005). Ao final do ensaio, foram feitos pools do líquido ruminal das vacas em cada $\mathrm{T}$ e dos diferentes períodos, para se mensurarem os ácidos graxos voláteis (AGV) e o nitrogênio amoniacal $\left(\mathrm{N}_{-} \mathrm{NH}^{3}\right)$ no rúmen. As amostras dos pools foram analisadas segundo a AOAC (Association..., 1997).

Os testes para as diferenças de médias foram realizados por meio de contrastes definidos previamente. Os contrastes avaliados foram: C.SMNM-C.SM: nitromineral menos concentrado e silagem de milho; C.SMNP-C.SM: nitroproteico menos concentrado e silagem de milho; C.SMNMC.SMNP: nitromineral menos nitroproteico; (C.SMNM+MO)- C.SMNM: nitromineral e monensina menos nitromineral; (C.SMNP+MO)C.SMNP: nitroproteico e monensina menos nitroproteico; (C. SMNP+MO)- C.SM: nitroproteico e monensina menos concentrado e silagem de milho, este somente para comparar consumo de matéria seca, digestibilidade da matéria seca, produção de leite e eficiência de produção. As médias foram comparadas entre os $\mathrm{T}$ utilizando-se o teste Tukey, a 5\% de probabilidade. As análises estatísticas foram realizadas utilizando-se o programa estatístico PROC GLM do pacote estatístico SAS (Statistical..., 2003).

\section{RESULTADOS E DISCUSSÃO}

A adição dos suplementos NP e NM à silagem de milho (C.SMNP) aumentou o CMS $(\mathrm{P}<0,05)$, mas não alterou a DMS em relação à do T C.SM $(\mathrm{P}>0,05 ; \mathrm{Tab} .1)$. As concentrações ruminais de propionato e butirato também aumentaram quando as vacas receberam os suplementos nitrogenados $(\mathrm{P}<0,05)$, no entanto a concentração de acetato não se alterou em nenhum dos $\mathrm{T}(\mathrm{P}>0,05)$ (Tab. 2 e 3), indicando maior atividade dos microrganismos ruminais, a qual poderia explicar o maior CMS $(\mathrm{P}<0,05)$, permitindo melhor utilização do $\mathrm{N}^{-\mathrm{NH}^{3}}$ e dos nutrientes (Tab. 2 e 3). Pereira et al. (2005) observaram que, à medida que se elevou a porcentagem de PB na dieta de vacas mestiças utilizando farelo de soja como fonte proteica, o CMS e a DMS aumentaram linearmente $(\mathrm{P}<0,05)$. Já Satter e Rofller (1981) afirmaram que a digestibilidade e a concentração da $\mathrm{PB}$ da 
dieta influenciaram a concentração de $\mathrm{N}-\mathrm{NH}^{3}$ no rúmen.

A adição de monensina aos T C.SMNP e C.SMNM (C.SMNP+MO e C.SMNM+MO) não alterou o CMS nem a DMS (P>0,05; Tab. 1). As produções de acetato, propionato e butirato no rúmen das vacas do $\mathrm{T}$ C.SMNM+MO não alteraram $(\mathrm{P}>0,05)$, mas a concentração de $\mathrm{N}$ $\mathrm{NH}^{3}$ aumentou em relação ao $\mathrm{T}$ C.SMNM $(\mathrm{P}<0,05)$. Entretanto, as concentrações de propionato e butirato no rúmen das vacas do $\mathrm{T}$ C.SMNP+MO reduziram $(\mathrm{P}<0,05)$ e a concentração de $\mathrm{N}^{-N_{H}}{ }^{3}$ não se alterou em relação ao T C.SMNP (P>0,05; Tab. 2 e 3$)$.

Estes resultados indicaram que o crescimento microbiano foi comprometido e que ocorreu alteração no ambiente ruminal, possivelmente devido à combinação de três fatores, como a suplementação proteica, o uso de monensina e a relação volumoso:concentrado (80:20). A monensina pode ter reduzido a população de bactérias que digerem parede celular (celulose e hemicelulose), dificultando, assim, a utilização dos nutrientes (energia) para o crescimento microbiano. De acordo com Satter (1986), a fibra pode limitar o acesso dos microrganismos às proteínas e aos carboidratos das forragens. A monensina, segundo Bergen e Bates (1984) e Duffield et al. (1997), pode reduzir a proteólise e aumentar o aporte de aminoácidos para o intestino, o qual poderia ter influenciado no aumento da proteína não degradada no rúmen (PNDR) quando as vacas foram suplementadas com suplemento à base de farelo de soja.

Com relação à produção de leite, os melhores resultados observados foram quando se adicionou ao C.SM o suplemento com maior concentração de farelo de soja (C.SMNP+MO e C.SMMNP vs. C.SM; 17,17 e 16,76 vs. 14,96kg/dia, respectivamente). Segundo Santos et al. (1998), o perfil, a qualidade dos aminoácidos e a concentração de PNDR contribuíram para aumentar a produção de leite em $0,7 \mathrm{~kg} /$ dia $(\mathrm{P}<0,05)$ e $2,7 \mathrm{~kg} / \mathrm{dia}$, quando se aumentou a concentração de PB (Ipharraquerre e Clark, 2005). O fluxo de aminoácidos essenciais (lisina e metionina) para o intestino aumentou com o aumento de PNDR na dieta (Santos et al., 1998). Conforme o NRC (National..., 2001), as melhores respostas em produção de leite por vacas em lactação são quando estas são suplementadas com aminoácidos essenciais, como a lisina e a metionina.

Nos $\mathrm{T}$ em que foi inserida monensina, a produção de leite não diferiu em relação aos $\mathrm{T}$ C.SMNM e C.SMNP (P>0,05; Tab. 1). O pequeno aumento na produção de leite observado no T C.SMNP+MO em relação ao C.SMNP se deve ao possível aumento no fluxo de aminoácidos essenciais que são gliconeogênicos, pois a contribuição do propionato foi menor $(\mathrm{P}<0,05$; Tab. 1).

Quanto à eficiência para produzir leite, observou-se que as vacas do T C.SM obtiveram melhor resultado do que as do T C.SMNM, não se observando diferença entre os demais $\mathrm{T}$ $(\mathrm{P}<0,05$; Tab. 1).

Com relação aos resultados dos parâmetros ruminais, a adição do suplemento NM continha $55 \%$ de ureia, fonte de nitrogênio não proteico. Para a boa utilização do nitrogênio advindo da ureia, é necessária uma fonte energética de disponibilidade rápida, e $\mathrm{o} \quad \mathrm{T}$ C.SM não disponibilizava essa energia no momento em que o NM foi adicionado à silagem de milho e oferecido às vacas após a ordenha. Observou-se que as vacas do $\mathrm{T}$ C.SMNM foram as que apresentaram maior concentração de $\mathrm{N}_{-} \mathrm{NH}^{3}$ no rúmen $(\mathrm{P}<0,05$; Tab. 2 e 3), demonstrando que, apesar da atividade dos microrganismos ruminais quanto à produção dos $\mathrm{AGVs}$, a energia vinda do C.SM não foi apropriada para que os microrganismos do rúmen usassem o nitrogênio disponível. Detmann et al. (2005) mencionaram que a suplementação utilizando ureia como fonte de nitrogênio aumentou a concentração de $\mathrm{N}$ $\mathrm{NH}^{3}(\mathrm{P}<0,05)$ no rúmen, não causou diferença na DMS nem na eficiência na síntese de proteína microbiana $(\mathrm{P}>0,05)$.

Ao se adicionar monensina ao $\mathrm{T}$ C.SMNM (C.SMNM+MO), o CMS e a DMS não se alteraram $(\mathrm{P}>0,05$; Tab. 1). As concentrações de acetato, propionato, butirato e $\mathrm{N}-\mathrm{NH}^{3}$ também não se alteraram $(\mathrm{P}>0,05)$. Com relação ao $\mathrm{pH}$ ruminal, não houve diferença entre nenhum dos $\mathrm{T}(\mathrm{P}>0,05$; Tab. 2 e 3$)$. 
Tabela 1. Médias ajustadas por grupo experimental e avaliação utilizando contrastes do consumo de matéria seca (CMS), digestibilidade da matéria seca (DMS), produção de leite (PL) e eficiência da produção de leite (EPL) de vacas F1 Holandês-Zebu alimentadas com concentrado e silagem de milho (C.SM), C.SM + nitromineral (C.SMNM), C.SM + nitroproteico (C.SMNP), C.SMNM + 250mg de monensina (C.SMNM+MO) ou C.SMNP + 250mg de monensina (C.SMNP+MO)

\begin{tabular}{|c|c|c|c|c|c|c|c|}
\hline Itens & C.SM & C.SMNM & C.SMNP & C.SMNM+MO & C.SMNP+MO & - & EPM* \\
\hline CMS & 12,46 & 14,38 & 14,59 & 14,91 & 14,51 & - & 0,50 \\
\hline DMS & 58,28 & 64,04 & 64,97 & 62,15 & 66,87 & - & 2,46 \\
\hline PL & 14,96 & 15,37 & 16,76 & 16,38 & 17,17 & - & 0,51 \\
\hline EPL & 1,25 & 1,07 & 1,16 & 1,14 & 1,19 & - & 0,05 \\
\hline Contraste & C.SMNP & C.SMNM & C.SMNM & C.SMNM+MO & C.SMNP+MO & C.SMNP+MO & $\mathrm{EE}^{* *}$ \\
\hline $\mathrm{s}$ & - C.SM & - C.SM & - C.SMNP & - C.SMNM & -C.SMNP & - C. SM & \\
\hline CMS & 2,12 & 1,92 & $-0,21$ & 0,52 & $-0,08$ & 2,04 & 0,71 \\
\hline DMS & 6,69 & 5,76 & $-0,93$ & $-1,88$ & 1,89 & 8,58 & 3,48 \\
\hline PL & 1,8033 & 0,4100 & $-1,3933$ & 1,0066 & 0,4100 & 2,21 & 0,72 \\
\hline EPL & $-0,088$ & $-0,182$ & $-0,094$ & 0,072 & 0,032 & 0,06 & 0,08 \\
\hline \multicolumn{8}{|c|}{ Valores de P relacionados aos contrastes } \\
\hline CMS & 0,0116 & 0,0198 & 0,7779 & 0,4789 & 0,9148 & 0,0198 & - \\
\hline DMS & 0,0784 & 0,1238 & 0,7929 & 0,5973 & 0,5966 & 0,0296 & - \\
\hline PL & 0,0151 & 0,5703 & 0,0577 & 0,1667 & 0,5703 & $\mathbf{0 , 0 0 3 3}$ & - \\
\hline EPL & 0,2695 & $\mathbf{0 , 0 3 3 9}$ & 0,2398 & 0,3622 & 0,6812 & 0,4754 & - \\
\hline
\end{tabular}

* EPM = Erro-padrão da média $. * * \mathrm{EE}=$ Erro do estimado.

Tabela 2. Médias ajustadas por tratamento dos parâmetros ruminais de vacas F1 Holandês-Zebu alimentadas com concentrado + silagem de milho (C.SM), C.SM + nitromineral (C.SMNM), C.SM + nitroproteico (C.SMNP) e C.SMNM e C.SMNP adicionados de monensina (MO) (250mg/diariamente)

\begin{tabular}{|c|c|c|c|c|c|c|}
\hline \multirow{2}{*}{ Itens } & \multicolumn{5}{|c|}{ Tratamentos } & \multirow[t]{2}{*}{ EPM* } \\
\hline & C.SM & C.SMNM & C.SMNP & C.SMNM+MO & C.SMNP+MO & \\
\hline Acetato** & 2,96 & 3,74 & 3,82 & 3,53 & 3,21 & 0,42 \\
\hline Propionato $* *$ & 0,64 & 1,03 & 1,14 & 1,08 & 0,69 & 0,11 \\
\hline Butirato** & 0,44 & 0,79 & 0,85 & 0,68 & 0,48 & 0,08 \\
\hline $\mathrm{AGVT}^{*} * *$ & 4,04 & 5,57 & 5,82 & 5,29 & 4,38 & 0,44 \\
\hline $\mathrm{pH}$ & 7,3 & 7,24 & 7,16 & 7,15 & 7,26 & 0,07 \\
\hline $\mathrm{N}-\mathrm{NH}^{3} * * * *$ & 5,41 & 7,87 & 6,73 & 6,91 & 7,58 & 0,59 \\
\hline
\end{tabular}

* EPM = Erro-padrão da média. ** Valores em Mmol/dL. *** Ácidos graxos voláteis totais.

**** Nitrogênio amoniacal em mg/dL.

Tabela 3. Avaliação por contrastes entre os tratamentos dos parâmetros ruminais de vacas F1 HolandêsZebu alimentadas com concentrado + silagem de milho (C.SM), C.SM + nitromineral (C.SMNM), C.SM + nitroproteico (C.SMNP) e C.SMNM e C.SMNP adicionados de monensina (MO) (250mg/diariamente)

\begin{tabular}{ccccccc}
\hline $\begin{array}{c}\text { Estimativas dos } \\
\text { contrastes }\end{array}$ & $\begin{array}{c}\text { C.SMNP } \\
\text { - C.SM }\end{array}$ & $\begin{array}{c}\text { C.SMNM } \\
\text { - C.SM }\end{array}$ & $\begin{array}{c}\text { C.SMNM } \\
\text { - C.SMNP }\end{array}$ & $\begin{array}{c}\text { C.SMNM+MO } \\
\text { - C.SMNM }\end{array}$ & $\begin{array}{c}\text { C.SMNP+MO } \\
\text { - C.SMNP }\end{array}$ & EE* $^{*}$ \\
\hline Acetato & 0,85 & 0,78 & $-0,08$ & $-0,21$ & 0,60 & 0,5898 \\
Propionato & 0,50 & 0,39 & $-0,11$ & 0,05 & $-0,46$ & 0,1573 \\
Butirato & 0,41 & 0,35 & $-0,06$ & $-0,11$ & $-0,38$ & 0,1188 \\
AGVT & 1,78 & 1,53 & $-0,25$ & $-0,28$ & $-1,44$ & 0,6255 \\
pH & $-0,1413$ & $-0,0600$ & 0,0813 & $-0,0940$ & 0,0986 & 0,0981 \\
N-NH3 & 1,3171 & 2,4595 & 1,1424 & $-0,9676$ & 0,8467 & 0,8438 \\
\hline \multicolumn{7}{c}{ Valores de P relacionados aos contrastes } \\
\hline Acetato & 0,1709 & 0,2096 & 0,8980 & 0,7258 & 0,3265 & - \\
Propionato & 0,0076 & 0,0278 & 0,4971 & 0,7725 & 0,0135 & - \\
Butirato & 0,0046 & 0,0117 & 0,6237 & 0,3549 & 0,0077 & - \\
AGVT & 0,0148 & 0,0306 & 0,7010 & 0,6601 & 0,0396 & - \\
pH & 0,1557 & 0,5435 & 0,4109 & 0,3424 & 0,3192 & - \\
N-NH3 & 0,1445 & 0,0130 & 0,2008 & 0,2738 & 0,3353 & - \\
\hline
\end{tabular}

* EE = Erro do estimado 


\section{CONCLUSÕES}

A adição do suplemento nitromineral ou nitroproteico à silagem de milho do tratamento concentrado durante a ordenha mais silagem de milho pós-ordenha aumentou o consumo de matéria seca.

A produção de leite foi maior quando vacas receberam o suplemento nitroproteico, entretanto a eficiência foi melhor nas vacas que não receberam suplemento nitromineral ou nitroproteico.

\section{AGRADECIMENTOS}

À Fapemig, pelo financiamento do projeto APQ 1938-2009; à Epamig, por ter cedido animais, instalações e parte da mão de obra; e ao CNPq, pela bolsa de estudos.

\section{REFERÊNCIAS}

ARIELI, A.; DICKEN, U.; DAGONI, I. et al. Production and helth of cows given monensin prepartum and a high-energy diet postpartum. $J$. Dairy Sci., v.91. p.1845-1851, 2008.

ASSOCIATION of official analytical chemists AOAC International - Official methods of analysis. 17.ed. Gaithersburg: AOAC, 1997.

BERGEN, W.G.; BATES, D.G. Ionophores: their effect on production efficiency and mode of action. J. Dairy Sci., v.58, p.1465-1483, 1984.

DETMANN, E.; PAULINO, M.F.; VALADARES FILHO, S.C. et al. Níveis de Proteína em Suplementos para Terminação de Bovinos em Pastejo Durante o Período de Transição Seca/Águas: Digestibilidade Aparente e Parâmetros do Metabolismo Ruminal e dos Compostos Nitrogenados. Rev. Bras. Zootec., v.34, p.1380-1391, 2005.

DUFFIELD, T.F.; SANDALS, D.; LESLIE, K. et al. Efficacy of monensin for the prevention of subclinical ketosis in lactating dairy cows. $J$. Dairy Sci., v.81, p.2866-2873, 1997.

HANEY Jr., M.E.; HOEHN, M.M. Monensin, a new biologically active compound. I. Discovery and isolation. Antimicrob. Agents Chemother, v.7, p.349-52, 1967.
IPHARRAGUERRE, I.R.; CLARK, J.H. Impacts of the Source and Amount of Crude Protein on the Intestinal Supply of Nitrogen Fractions and Performance of Dairy Cows. J. Dairy Sci., v.88, p.22-37, 2005.

LEMENAGER, R.P; OWENS, F.N; LUSBY, K.S; TOTUSEK, R. Monensin, intake forage and lactation of range beef cows. J. Anim. Sci., v.47, p.247-254, 1978.

NATIONAL research council - NRC. Nutrient requirements of dairy cattle. 7.ed.. National Academy Press, 2001. p.381.

OLIVEIRA, M.V.M.; LANA, R.P.; FREITAS, A.W.P. et al. Parâmetros ruminal, sanguíneo, urinário e digestibilidade de nutrientes em novilhas leiteiras recebendo diferentes níveis de monensina. Rev. Bras. Zootec. v.34, p.21432154, 2005.

PEREIRA, M.L.A.; VALADARES FILHO, S.C; VALADARES, R.F.D et al. Consumo, digestibilidade aparente total, produção e composição do leite em vacas no terço inicial da lactação alimentadas com níveis crescentes de proteína bruta no concentrado. Rev. Bras. Zootec., v.34, p.1029-1039, 2005.

SANTOS, F.A.P.; SANTOS, J.E.P.; THEURER, C.B. et al. Effects of Rumen-Undegradable Protein on Dairy Cow Performance: A 12-Year Literature Review. J. Dairy Sci., v.81, p.31823213, 1998.

SATTER, L.D. Protein Supply from Undegraded Dietary Protein. Symposium: Protein And Fiber Digestion, Passage And Utilization In Lactating Cows. J. Dairy Sci., v.69. p.2734-2749, 1986.

SATTER, L.D.; ROFFLER, R.E. Influence of nitrogen and carbohydrate inputs on rumen fermentation. Recent developments in Ruminant Nutrition. 1.ed., 1981. p.115-139.

SILVA, J.J.; SALIBA, H.O.S.; BORGES, I. et $a l$. Indicadores para estimativa de consumo total por novilhas Holandês-Zebu mantidas em confinamento. Rev. Bras. Saúde Prod. Anim., v.11, p.838-848, 2010.

VAN DER WERF, J.H.J.; JONKER, L.J.; OLDENBROEK, J.K. Effect of monensin on milk production by Holstein and Jersey cows. $J$. Dairy Sci., v.81, p.427-433, 1998.

VAN SOEST, P.J. Nutritional ecology of the ruminant. Cornell University. 2.ed., 1991. 476p. 